\title{
The prevalence and impact of self-reported foot and ankle pain in the over 55 age group: a secondary data analysis from a large community sample
}

\author{
Anne-Maree Keenan ${ }^{1 *}$ (D), Chris Drake ${ }^{2}$, Philip G. Conaghan ${ }^{3}$ and Alan Tennant ${ }^{4}$
}

\begin{abstract}
Background: While the prevalence and impact of musculoskeletal problems are high, most attention has been directed towards the back, knee and hip disorders. Foot pain is known to be common in older adults and accounts for a significant burden on health services. The aim of this study was to assess the impact of foot and ankle joint pain, considering age, presence of co-morbidities and other site joint pain, in a large community sample.

Methods: In the North Yorkshire Health study, 16,222 people over 55 years participated in a detailed survey of the prevalence and impact of lower limb joint problems. Self-assessment of overall body pain and functional activities of daily living were assessed. Participants indicated the presence of joint pain, stiffness or swelling during the last 3 months which had lasted for more than 6 weeks on a manikin: data were captured on the foot and the ankle.

Results: The prevalence of self-reported foot and ankle joint pain was substantial: 184.33 per 1000, second only to knee problems. While foot pain was common, it was mostly associated with joint pain at other sites; only 1 in 11 of those with foot and ankle pain reported it only in the foot. Logistic regression modeling revealed while established factors such as co-morbidities, knee and hip problems contributed to functional impairment, foot and ankle problems contributed to an additional increased risk of having difficulty standing and walking by two fold (OR $=$ $2.314,95 \% \mathrm{Cl} 2.061-2.598)$, going up and down stairs by $71 \%(\mathrm{OR}=1.711,95 \% \mathrm{Cl} 1.478-1.980)$ and getting up from a seated position by $44 \%$ (OR $=1.438,95 \% \mathrm{Cl} 1.197-1.729)$.
\end{abstract}

Conclusion: These results suggest that not only are foot problems in the over 55 age group extremely prevalent, they have a considerable impact on functional abilities.

Keywords: Foot pain, Joint pain, Musculoskeletal pain, Functional ability

\section{Background}

Musculoskeletal disease presents a significant global burden and is the second leading cause of years lost to disability [1] . While the prevalence, impact and future burden of back, knee and hip pain have been well reported, equivalent data on foot pain have been limited until relatively recently. Foot pain is now known to be highly prevalent in older adults in the general community, and more common in females [2-5]. Body mass

\footnotetext{
* Correspondence: a.keenan@leeds.ac.uk

${ }^{1} \mathrm{NIHR}$ Leeds Biomedical Research Centre, Leeds Teaching Hospitals Trust,

School of Healthcare, University of Leeds, Leeds, England

Full list of author information is available at the end of the article
}

index (BMI) appears to be a strong predictor of foot pain $[6,7]$, with other predictors including, arthritis and previous foot pain [6]. The burden on health services is high, with foot and ankle complaints accounting for between 3 and $8 \%$ of UK primary care musculoskeletal consultations $[8,9]$. However, the impact and burden of foot and ankle joint pain on activities of daily living has yet to be determined.

In the 1990s, a regional UK study was performed to determine the prevalence of knee problems in people over age 55 in the community; results of this survey on the prevalence and impact of hip and knee pain and multiple site joint pain have been previously reported

(c) The Author(s). 2019 Open Access This article is distributed under the terms of the Creative Commons Attribution 4.0 International License (http://creativecommons.org/licenses/by/4.0/), which permits unrestricted use, distribution, and 
[10-12]. The aim of this current study was therefore, undertaking further secondary analysis of the data, to determine the prevalence of self-reported foot and ankle joint pain in the community and its impact on important functional capabilities when present alone, or in conjunction with other common factors which also affect the activities of daily living, include co-morbidities and joint pain in other anatomical locations. Previous publications from this data have included the prevalence and impact of hip [10], knee pain [11], and multi-joint pain [12], which found the impact of multiple joint pain is substantial and greater than simply just an additive of combining the impact of single joint problems. The aim of this paper is to describe the prevalence and impact of foot pain on activities of daily living.

\section{Methods}

As described previously [11], 18,827 participants over the age of 55 years were randomly selected from the North Yorkshire Family Health Services Authority (population of 210,00) and were sent a questionnaire through the post. Generic demographic information (age, gender), the presence of co-morbidities (self-reported co-morbidities that had been diagnosed by a health care professional) and activities of daily living were collected (Table 1). Participants were also asked to indicate the location of joint pain, stiffness or swelling last 3 months which had lasted for more than 6 weeks on a manikin. The foot region had two boxes: one for the foot and one for the ankle. However, following feedback from a patient focus group to explore the fidelity of interpretation for our secondary analysis, there was concern that people would not be able to discriminate pain in the ankle from pain in the foot. Therefore, we

Table 1 Stem questions for co-morbidities and activities of daily living and disability [12]

\begin{tabular}{|c|c|c|}
\hline \multicolumn{3}{|l|}{ Co-morbidities } \\
\hline \multicolumn{3}{|c|}{ Have you ever been told by a doctor or other health professional: } \\
\hline That you have arthritis or rheumatism? & $\square$ Yes & $\square \mathrm{No}$ \\
\hline That you have high blood pressure? & $\square$ Yes & $\square \mathrm{No}$ \\
\hline That you have diabetes? & $\square$ Yes & $\square \mathrm{No}$ \\
\hline That you have had a stroke? & $\square$ Yes & $\square \mathrm{No}$ \\
\hline \multicolumn{3}{|l|}{ Functional ability } \\
\hline \multicolumn{3}{|c|}{$\begin{array}{l}\text { In the last three months, have you ha any difficulties with any of the } \\
\text { following activities because of health problems or disabilities? }\end{array}$} \\
\hline Gripping or holding things & $\square$ Yes & $\square \mathrm{No}$ \\
\hline Brushing or combing your hair & $\square$ Yes & $\square \mathrm{No}$ \\
\hline Getting up and down stairs & $\square$ Yes & $\square \mathrm{No}$ \\
\hline Getting up from a chair or the toilet & $\square$ Yes & $\square \mathrm{No}$ \\
\hline Putting on shoes, socks or stockings & $\square$ Yes & $\square \mathrm{No}$ \\
\hline Standing or walking & $\square$ Yes & $\square \mathrm{No}$ \\
\hline
\end{tabular}

combined all foot and ankle data into one item termed 'foot pain' which represented foot and ankle pain. The questionnaire provided the basis of several publications including the prevalence and impact of multiple site joint pain [12]. This current study aims to determine specifically the prevalence and impact of foot and ankle joint pain.

\section{Statistical analysis}

The data were explored for non- responder bias and found those who responded were more likely to be female and slightly younger: prevalence data were therefore weighted by gender and age [12]. Unweighted data were used for all modelling and inferential analysis. The presence of foot pain, gender, age and the presence of one or more self-reported healthcare diagnosed comorbidity, were included in a forward, step-wise regression analysis [12]. Variables were investigated for both main and interaction effects and the summative odd risks for joint combinations included the main and interaction effect of the joints involved and based on that described in the literature [13, 14]. Data were analyzed using SPSS Statistics Version 25.

\section{Results}

Completed questionnaires were received from 16,222 people (response rate $86 \%$ ). The prevalence of foot and ankle problems was 184.33 per $1000(95 \% \mathrm{CI}= \pm 24.033)$, with a greater number of women $\left(x^{2}=980.994, d f=1, \mathrm{p}\right.$ $\leq 0.001)$ and older people $\left(x^{2}=307.218, d f=2, \mathrm{p} \leq\right.$ 0.001 ) reporting foot problems (Table 2). Importantly, foot and ankle pain in isolation (ie not associated with

Table 2 Prevalence estimates of joint pain, swelling and/or stiffness over the last 3 months, lasting for more than 6 weeks, age and comorbidities, per 1000 [12]

\begin{tabular}{llll}
\hline Site & Male & Female & Total \\
\hline Knee & 176.64 & 253.92 & 220.33 \\
& $162.62-190.66$ & $238.20-269.64$ & $205.26-235.40$ \\
Foot and ankle & 136.28 & 221.28 & 184.33 \\
& $123.47-149.09$ & $206.19-236.37$ & $170.11-198.55$ \\
Back & 134.33 & 183.48 & 162.12 \\
& $121.59-147.07$ & $169.28-197.68$ & $148.51-175.73$ \\
Hip & 94.43 & 151.53 & 126.71 \\
& $83.22-105.64$ & $138.23-164.83$ & $114.23-139.19$ \\
Age: 55 to 64 yrs & 334.67 & 389.73 & 362.73 \\
& $317.78-351.55$ & $372.35-407.11$ & $345.57-379.89$ \\
65 to 75 yrs & 337.26 & 401.64 & 372.49 \\
& $320.35-354.17$ & $384.18-419.10$ & $355.24-389.75$ \\
75 year plus & 311.56 & 460.80 & 409.71 \\
Co morbidities & $294.95-328.17$ & $443.08-478.52$ & $392.20-427.23$ \\
& 352.14 & 444.56 & 404.39 \\
\hline
\end{tabular}

Estimates have been adjusted for age and gender with the upper and lower $95 \%$ confidence intervals presented in italics 
any other sites of joint pain) was uncommon, with only one in 11 of those with foot pain reporting it in the foot alone, a prevalence of only 4.87 per $1000(95 \% \mathrm{CI}= \pm$ 4.314). The most common combination of foot pain with other joints were feet and knees; feet, knees and hands; and feet knees and hips; feet and hands. Summary logistic regression tables for each of the functional indicators are included in Table 3.
As we have previously reported [12], the impact of multiple sites of joint pain is substantial: for example, those with knee and foot pain (the most common of the multiple site pain presentation) increased the difficulty of walking and standing 14-fold. As the previous publication reported the data for multiple site prevalence and impact, this paper reports the impact of foot and ankle pain, regardless of which other sites were involved and

Table 3 Summary Logistic Regression Table for the impact of site of joint pain on activities of daily living

\begin{tabular}{|c|c|c|c|c|c|c|c|}
\hline & Variable & Co-ef $(\beta)$ & Stan. Error & Wald & $P$ & OR & $95 \% \mathrm{Cl}$ \\
\hline \multicolumn{8}{|c|}{ Standing and Walking } \\
\hline \multirow[t]{9}{*}{ Main effects } & Constant & -2.232 & 0.162 & - & - & - & - \\
\hline & Foot and ankle & 0.839 & 0.059 & 201.74 & 0.000 & 2.314 & 2.061 to 2.598 \\
\hline & Hip & 0.868 & 0.066 & 172.030 & 0.000 & 2.382 & 2.093 to 2.712 \\
\hline & Co morbidities & 1.751 & 0.134 & 171.872 & 0.000 & 5.761 & 4.434 to 7.486 \\
\hline & Knee & 1.006 & 0.093 & 117.247 & 0.000 & 2.734 & 2.279 to 3.280 \\
\hline & Back & 0.403 & 0.060 & 45.336 & 0.000 & 1.496 & 1.331 to 1.683 \\
\hline & Foot and ankle & 0.8745 & 0.1118 & 61.2101 & 0.000 & 2.398 & 1.926 to 2.985 \\
\hline & Gender & 0.945 & 0.191 & 24.501 & 0.000 & 2.573 & 1.770 to 3.742 \\
\hline & Age: 55 to $64 \mathrm{yrs}$ & -0.522 & 0.121 & 18.626 & 0.000 & 0.593 & 0.468 to 0.752 \\
\hline \multirow[t]{2}{*}{ Int } & Gender (male) by age: 55 to 64 yrs & -0.628 & 0.151 & 17.389 & 0.000 & 0.534 & 0.397 to 0.717 \\
\hline & Co morbidity by Gender & -0.435 & 0.162 & 7.210 & 0.007 & 0.648 & 0.472 to 0.889 \\
\hline \multicolumn{8}{|c|}{ Going up and down stairs } \\
\hline \multirow[t]{7}{*}{ Main effects } & Constant & -2.199 & 0.142 & - & - & - & - \\
\hline & Co morbidities & 1.509 & 0.101 & 225.088 & 0.000 & 4.524 & 3.714 to 5.510 \\
\hline & Age: 55 to 64 years & -1.122 & 0.143 & 61.364 & 0.000 & 0.326 & 0.246 to 0.431 \\
\hline & Knee & 0.710 & 0.098 & 52.093 & 0.000 & 2.033 & 1.677 to 2.465 \\
\hline & Foot and ankle & 0.537 & 0.075 & 51.755 & 0.000 & 1.711 & 1.478 to 1.980 \\
\hline & Hip & 1.021 & 0.162 & 39.974 & 0.000 & 2.777 & 2.023 to 3.811 \\
\hline & Back & 0.330 & 0.108 & 9.358 & 0.000 & 1.390 & 1.126 to 1.717 \\
\hline \multirow[t]{3}{*}{ Int } & Knee by Age: 55 to 64 yrs & 0.604 & 0.143 & 17.793 & 0.000 & 1.829 & 1.382 to 2.422 \\
\hline & Gender (Male) by Age: 55 to 64 & -0.474 & 0.149 & 10.100 & 0.001 & 0.623 & 0.465 to 0.834 \\
\hline & Gender (Male) by back & -0.417 & 0.121 & 11.841 & 0.001 & 0.659 & 0.520 to 0.836 \\
\hline \multicolumn{8}{|c|}{ Getting up from a chair/toilet } \\
\hline \multirow[t]{8}{*}{ Main } & Constant & -1.974 & 0.146 & - & - & - & - \\
\hline & Co morbidities & 1.100 & 0.101 & 117.519 & 0.000 & 3.004 & 2.462 to 3.664 \\
\hline & Hip & 1.623 & 0.196 & 68.783 & 0.000 & 5.066 & 3.453 to 7.434 \\
\hline & Age: 55 to $64 \mathrm{yrs}$ & -1.242 & 0.157 & 62.324 & 0.000 & 0.289 & 0.212 to 0.393 \\
\hline & Foot and ankle & 0.363 & 0.094 & 14.999 & 0.000 & 1.438 & 1.197 to 1.729 \\
\hline & Gender (Male) & 0.380 & 0.110 & 11.850 & 0.001 & 1.462 & 1.178 to 1.814 \\
\hline & Knee & 0.382 & 0.118 & 10.585 & 0.001 & 1.466 & 1.164 to 1.845 \\
\hline & Back & 0.362 & 0.119 & 9.271 & 0.002 & 1.436 & 1.138 to 1.813 \\
\hline \multirow[t]{3}{*}{ Int } & Knee by Age: 55 to $64 \mathrm{yrs}$ & 0.634 & 0.145 & 19.179 & 0.000 & 1.885 & 1.419 to 2.503 \\
\hline & Back by Age: 55 to $64 \mathrm{yrs}$ & 0.494 & 0.142 & 12.022 & 0.001 & 1.638 & 1.239 to 2.165 \\
\hline & Gender by Age: 55 to 64 yrs & -0.525 & 0.150 & 12.237 & 0.000 & 0.591 & 0.441 to 0.794 \\
\hline
\end{tabular}

Included are the summary of the main effects and interactions for each of the major sites of OA, with foot and ankle joint pain in italics. Abbreviations: co-eff $(\beta)=$ the mathematical weighting of each variable in the model; Stan Error = the estimated error of the mathematical weighting; OR $=$ odds ratio; $95 \% \mathrm{Cl}=$ the $95 \%$ confidence interval for the estimated odds ratio; int = interaction effects 
compare that to the other major sites of joint involvement.

Of note, the presence of self-reported, health care diagnosed co-morbidity had the greatest impact on activities of daily living, which we have discussed in detail in our previous publication [12]. While the importance of co-morbidity is undoubtedly substantial, care should be taken with interpreting the magnitude of the impact of co-morbidities across activities of daily living, given the potential confounding influence of co-morbidities across different activities.

For standing and walking, in addition to comorbidities, the greatest predictor of who would report difficulty was the presence of knee pain, who were almost three times more likely to report difficulty $\left(\mathrm{R}^{2}=\right.$ $0.324, \mathrm{OR}=2.734, \mathrm{p} \leq 0.001,95 \% \mathrm{CI}=1.713-2.716)$. Of note, however, foot and ankle pain increased the risk of reported difficulty by almost two and a half times (OR = $2.314, p \leq 0.001,95 \% \mathrm{CI}=1.349-1.993)$, which was an equivalent risk to hip problems $(\mathrm{OR}=2.382, p \leq 0.001$, $95 \% \mathrm{CI}=2.353-3.513)$, and higher than those who reported back problems $(\mathrm{OR}=1.496, p \leq 0.001,95 \% \mathrm{CI}=$ 1.5910-2.3593).

People with knee and hip problems were two and over two and a half times respectively more likely to report difficulty in climbing up or down stairs $(\mathrm{OR}=2.033, p \leq$ $0.001,95 \% \mathrm{CI}=2.8012-4.2896 ; \mathrm{OR}=2.777, \mathrm{p} \leq 0.001$, $95 \% \mathrm{CI}=2.0263-3.3062$ ). While these were the greatest predictors of problems, those with foot and ankle problems were $71 \%$ more likely to experience difficulty (OR = $1.711, \mathrm{p} \leq 0.001,95 \% \mathrm{CI}=1.9260-2.9851)$, which is once again, a greater risk than those who had back problems $(\mathrm{OR}=1.390, \mathrm{p} \leq 0.001,95 \% \mathrm{CI}=1.1640-1.7036)$.

In the task of rising from a seated position (the chair or the toilet), the presence of hip problems was the greatest predictor of difficulty $(\mathrm{OR}=5.066, \mathrm{p} \leq 0.001$, $95 \% \mathrm{CI}=2.2313-4.3964)$. Foot and ankle problems increased the difficulty in rising from a seated position to a high risk by $44 \%(\mathrm{OR}=1.438,95 \% \mathrm{CI}=1.197-1.729$, $\mathrm{p}$ $\leq 0.001$ ), which was slightly more than to knee and back problems.

\section{Discussion}

The purpose of this paper was to interrogate an existing, unique and large data set to explore the prevalence and impact of foot and ankle related pain in a community based cohort of people over the age of 55. The prevalence of foot and ankle problems was 184.33 per thousand, with a greater number of women and older people reporting foot problems which is consistent with other studies [2, 3, 5, 15-17]. Of note, foot and ankle joint pain was the third most common site of self-reported joint pain, behind only knee (220.33 per 1000) and wrist/hand pain (190.09 per 1000) as reported in our previous publication [12], and the second most common single joint presentation behind knee. Importantly, as reported in our previous paper, isolated foot related pain was relatively uncommon, with only 1 in 38 of those with foot pain having foot pain alone [12]. As described previously, the most common combination of foot pain with other joints were feet and knees; feet, knees and hands; and feet knees and hips; feet and hands; and the combination of joint problems had a substantial impact on the activities of daily living, indicating that there was an interaction effect of multiple joint pain above and beyond a simply what was seen with single site involvement [12].

As we described in our previous publication, there was a correlation between increasing number of sites of pain and impairment of daily activities. However, this was not simply an additive issue (ie the more sites of pain, the greater the impact) but an exponential increase in difficulty with different combinations of sites of joint pain. Unsurprisingly, was the joint combination that had the most substantial impact was a combination of knee, back, foot/ankle, and hip pain [12]. Other joint combinations that included the foot and ankle which increased the risk of impact on daily activities were the hip and foot, knee and foot/ankle; and knee, hip and foot/ankle. The current results and those of Finney et al. [3], indicate that specific health care attention should be paid to foot and ankle complaints in addition to other more commonly reported joint problems.

In this study, co-morbidities were found to be the single most significant predictor of who would report difficulty in walking, climbing stairs and standing. Previously, in a large UK survey, half of all severe disability in the community came from stroke and arthritis [18]. More recently, a study of those who had survived a stroke found that almost half (47\%) had musculoskeletal problems [19]. In the current study, only the hip was greater than co-morbidities as the single most influential variable on rising from a seated position. While these were the greatest predictors of problems, those with foot and ankle problems were $44 \%$ more likely to experience difficulty which is a greater risk than those who had back problems. This is significant as low back pain is well established as causing more global disability than other any other condition [20].

While not the primary purpose of the initial survey, there are several key elements which support this additional analysis. First, the response rate of $86 \%$, higher in this study than other comparable studies [2, 3, 5, 15-17] and the large cohort of people aged over 55, offers a unique and robust platform to explore the impact of foot pathology. Second, the impact of foot joint pain in either isolation, or in combination with other common joint patterns, on activities of daily living has not been 
previously reported. Finally, this analysis provides the contextual information of the importance of the foot in the context of other, more commonly reported joints.

The limitations of this study are acknowledged. This is a secondary analysis of a large community cohort and was not the primary purpose of the study design and also the data were collected over 20 years ago. Thus, while it is possible that the age-specific prevalence has not changed, the ageing of the population will mean that raw numbers will have increased. The issue of comorbidities is important: as a questionnaire, selfreported health professional diagnosed co-morbidities have been include, which has limitations. Our data does, however the prevalence figures in this study are comparative to similar reports of multi-site joint pain [3]. Furthermore, we have only included a count of the number of co-morbidities: there would be great merit in looking at individual or groups of co-morbidities and their impact. Finally, we also recognize that other variables that were not considered in the logistic regression modelling may also be likely to impact on functional ability.

\section{Conclusion}

The functional ability of people over the age of 55 is multifaceted, with the presence of existing medical problems and age influencing difficulty in undertaking daily activities. Foot and ankle joint pain are common, and contribute to functional impairment and commonly occur with other sites of joint pain. As treatments for foot pain have been demonstrated to be effective, foot and ankle problems should be considered in the overall assessment and management of impairment through appropriate multi-disciplinary approach.

\section{Acknowledgements \\ We would like to thank all the participants who gave their time to complete the surveys and Jon Fear who was responsible for gaining the funding for the North Yorkshire survey. AMK and PGC are supported in part by the UK NIHR Leeds Biomedical Research Centre. The views expressed are those of the authors and not necessarily those of the NHS, the NIHR, or the Department of Health.}

\section{Authors' contributions}

A-MK participated in the "The prevalence and impact of self-reported foot and ankle pain in the over 55 age group: a secondary data analysis" and has seen and approved the final version. A-MK participated in the design, analysis and interpretation of this study and was the main author on this paper. A-MK was the first author for a previous study using the North Yorkshire database [12]. A-MK is the guarantor for this paper. CD participated in the "The prevalence and impact of self-reported foot and ankle pain in the over 55 age group: a secondary data analysis" and has seen and approved the final version. CD participated in interpretation of this study and contributed to writing this paper. AT participated in the "The prevalence and impact of self-reported foot and ankle pain in the over 55 age group: a secondary data analysis" and has seen and approved the final version. AT participated in the conception, design, analysis and interpretation of this study and contributed to the writing of the paper. AT has been involved in three previous publications using the North Yorkshire database [10-12]. PGC participated in the "The prevalence and impact of self-reported foot and ankle pain in the over
55 age group: a secondary data analysis" and has seen and approved the final version. PGC participated in the design, analysis and interpretation of this study and contributed to the writing of the paper. PGC has been involved in a previous publication using the North Yorkshire database [12]. All authors read and approved the final manuscript

\section{Funding}

The original study was funded by the North Yorkshire Health Authority. All current authors/contributors were independent from North Yorkshire Health.

\section{Availability of data and materials}

The datasets used and/or analysed during the current study are available from the corresponding author on reasonable request.

Ethics approval and consent to participate

Ethics approval was gained for the original study through the North Yorkshire Local Research Ethics Committee in the United Kingdom.

\section{Consent for publication}

NA

\section{Competing interests}

The authors declare they have no competing interests.

\section{Author details}

${ }^{1} \mathrm{NIHR}$ Leeds Biomedical Research Centre, Leeds Teaching Hospitals Trust, School of Healthcare, University of Leeds, Leeds, England. ${ }^{2}$ Mid Yorkshire Hospitals NHS Trust, NIHR Leeds Biomedical Research Centre, Leeds, England. ${ }^{3}$ Leeds Institute of Rheumatic and Musculoskeletal Medicine, NIHR Leeds Biomedical Research Centre, Leeds Teaching Hospitals Trust, University of Leeds, Leeds, England. ' Leeds Institute of Rheumatic and Musculoskeletal Medicine, University of Leeds, Leeds, England.

Received: 19 July 2019 Accepted: 1 November 2019

Published online: 15 November 2019

\section{References}

1. Vos T, et al. Global, regional, and national incidence, prevalence, and years lived with disability for 310 diseases and injuries, 1990-2015: a systematic analysis for the global burden of disease study 2015. Lancet. 2016; 388(10053):1545-602.

2. Hill CL, et al. Prevalence and correlates of foot pain in a population-based study: the north West Adelaide health study. J Foot Ankle Res. 2008;1(1):1-7.

3. Finney $A$, et al. Multisite peripheral joint pain: a cross-sectional study of prevalence and impact on general health, quality of life, pain intensity and consultation behaviour. BMC Musculoskelet Disord. 2017;18(1):535.

4. Wranker LS, Rennemark M, Berglund J. Pain among older adults from a gender perspective: findings from the Swedish National Study on aging and care (SNAC-Blekinge). Scand J Public Health. 2016;44(3):258-63.

5. Molgaard C, Lundbye-Christensen S, Simonsen O. High prevalence of foot problems in the Danish population: a survey of causes and associations. Foot (Edinb). 2010;20(1):7-11.

6. Gill TK, et al. Predictors of foot pain in the community: the north West Adelaide health study. J Foot Ankle Res. 2016;9(1):1-8.

7. Gay A, et al. Associations between body mass index and foot joint pain in middle-aged and older women: a longitudinal population-based cohort study. Arthritis Care Res. 2014;66(12):1873-9.

8. Menz HB, et al. Characteristics of primary care consultations for musculoskeletal foot and ankle problems in the UK. Rheumatology. 2010; 49(7):1391-8.

9. Ferguson $\mathrm{R}$, et al. Encounters for foot and ankle pain in UK primary care: a population-based cohort study of CPRD data. Br J Gen Pract. 2019;69(683): e422-9.

10. Fear J, et al. Prevalence of hip problems in the population aged 55 years and over: access to specialist care and future demand for hip arthroplasty. Rheumatology. 1997;36(1):74-6.

11. Tennant A, et al. Prevalence of knee problems in the population aged 55 years and over: identifying the need for knee arthroplasty. Br Med J. 1995; 310:1291-3.

12. Keenan $\mathrm{AM}$, et al. Multiple joint problems in the population: prevalence and impact on function. Arthritis Rheum. 2006;55(5):757-64. 
13. Kleinbaum DG, Klein M. In: Dietz K, et al., editors. Logistic Regression. A selflearning text. Statistics for biology and health. New York: Springer-Verlag; 2002.

14. Glantz SA, Slinker BK. Primer of applied regression and analysis of variance. New York: McGraw-Hill Inc; 1990.

15. Garrow AP, Silman AJ, Macfarlane GJ. The Cheshire foot pain and disability survey: a population survey assessing prevalence and associations. Pain. 2004;110:378-84.

16. Thomas E, et al. The north Staffordshire osteoarthritis project--NorStOP: prospective, 3-year study of the epidemiology and management of clinical osteoarthritis in a general population of older adults. BMC Musculoskelet Disord. 2004;5(1):2

17. Roddy E, Muller S, Thomas E. Onset and persistence of disabling foot pain in community-dwelling older adults over a 3-year period: A prospective cohort study. J Gerontol A Biol Sci Med Sci. 2011;66 A(4):474-80.

18. Badley EM, Wood PHN, Thompson RP. The prevalence and severity of major disabling conditions - a reappraisal of the government social survey on the handicapped and impaired in Great Britain. Int J Epidemiol. 1978;7(2):14551.

19. Hettiarachchi $C$, et al. Prevalence and impact of joint symptoms in people with stroke aged 55 years and over. J Rehabil Med. 2011;43(3):197-203.

20. Hoy D, et al. The global burden of low back pain: estimates from the global burden of disease 2010 study. Ann Rheum Dis. 2014;73(6):968-74.

\section{Publisher's Note}

Springer Nature remains neutral with regard to jurisdictional claims in published maps and institutional affiliations.

Ready to submit your research? Choose BMC and benefit from:

- fast, convenient online submission

- thorough peer review by experienced researchers in your field

- rapid publication on acceptance

- support for research data, including large and complex data types

- gold Open Access which fosters wider collaboration and increased citations

- maximum visibility for your research: over $100 \mathrm{M}$ website views per year

At BMC, research is always in progress.

Learn more biomedcentral.com/submissions 